\title{
Three-Dimensional Intraarterial Vaso Computed Tomography Depiction of Pipeline Flex with Shield Technology Flow Diverter Stent in Ruptured Blister Aneurysm of Supraclinoid Internal Carotid Artery
}

\author{
Rasmiranjan Padhi ${ }^{1}$ Sathish Kandasamy ${ }^{10}$ \\ ${ }^{1}$ Department of Imaging Services and Interventional Radiology, $C$ \\ Kuppuswamy Naidu Memorial Hospital, Coimbatore, Tamil Nadu, \\ India \\ 2 Department of Neurosurgery, G Kuppuswamy Naidu Memorial \\ Hospital, Coimbatore, Tamil Nadu, India
}

\author{
BalaSenthil Kumaran²
}

J Clin Interv Radiol ISVIR 2022;6:152-153.

\author{
Address for correspondence Rasmiranjan Padhi, Chief Consultant, \\ Neurointerventional Unit, G Kuppuswamy Naidu Memorial Hospital, \\ Coimbatore, Tamil Nadu, India \\ (e-mail: rasmiranjan1985@gmail.com; \\ sathisam@gmail.com; drbsk@gknmh.org).
}

\begin{abstract}
Keywords

- Vaso CT

- pipeline flex

- flow diverter

Blister aneurysms are intracranial arterial lesions originating at nonbranching sites of the dorsal supraclinoid internal carotid artery and basilar artery. ${ }^{1}$ Among different treatment options, the use of flow-diverting devices is gaining popularity and has the potential for becoming the standard of care. ${ }^{2}$

Radiological evaluation of flow diverter braid expansion and vessel wall apposition during procedure has become useful in preventing life-threatening complications. Incomplete coverage of an aneurysm neck, kinking, or incomplete expansion and malapposition of a stent carries a significant risk for thromboembolic events. ${ }^{3,4}$
\end{abstract}

Blister aneurysms are intracranial arterial lesions originating at nonbranching sites of the dorsal supraclinoid internal carotid artery (ICA) and basilar artery. ${ }^{1}$ Among different treatment options, the use of flow-diverting devices is gaining in popularity and has the potential for becoming the standard of care. ${ }^{2}$

Radiological evaluation of flow diverter braid expansion and vessel wall apposition during procedure has become useful in preventing life-threatening complications. Incomplete coverage of an aneurysm neck, kinking, or incomplete expansion and malapposition of a stent carries a significant risk for thromboembolic events. ${ }^{3,4}$
We present a case of ruptured blister aneurysm of right supraclinoid ICA treated by pipeline flex device with shield technology (-Figs. 1 and 2) in Philips Azurion 7B 20/15 Clarity IQ Biplane cathlab (Philips healthcare, Netherlands).

The injection protocol used for intraarterial Vaso computed tomography was as follows:

- Total volume of contrast used-55 mL

- Dilution of contrast-10\% (10 mL iohexol $350 \mathrm{mg}+90 \mathrm{~mL}$ normal saline)

- Acquisition time-20 seconds, X-ray delay-2 seconds, PSI-300. published online

October 5, 2021
DOI https://doi.org/

$10.1055 / \mathrm{s}-0041-1732847$.

ISSN 2457-0214. (c) 2021. Indian Society of Vascular and Interventional Radiology. All rights reserved.

This is an open access article published by Thieme under the terms of the Creative Commons Attribution-NonDerivative-NonCommercial-License, permitting copying and reproduction so long as the original work is given appropriate credit. Contents may not be used for commercial purposes, or adapted, remixed, transformed or built upon. (https://creativecommons.org/ licenses/by-nc-nd/4.0/)

Thieme Medical and Scientific Publishers Pvt. Ltd., A-12, 2nd Floor, Sector 2, Noida-201301 UP, India 


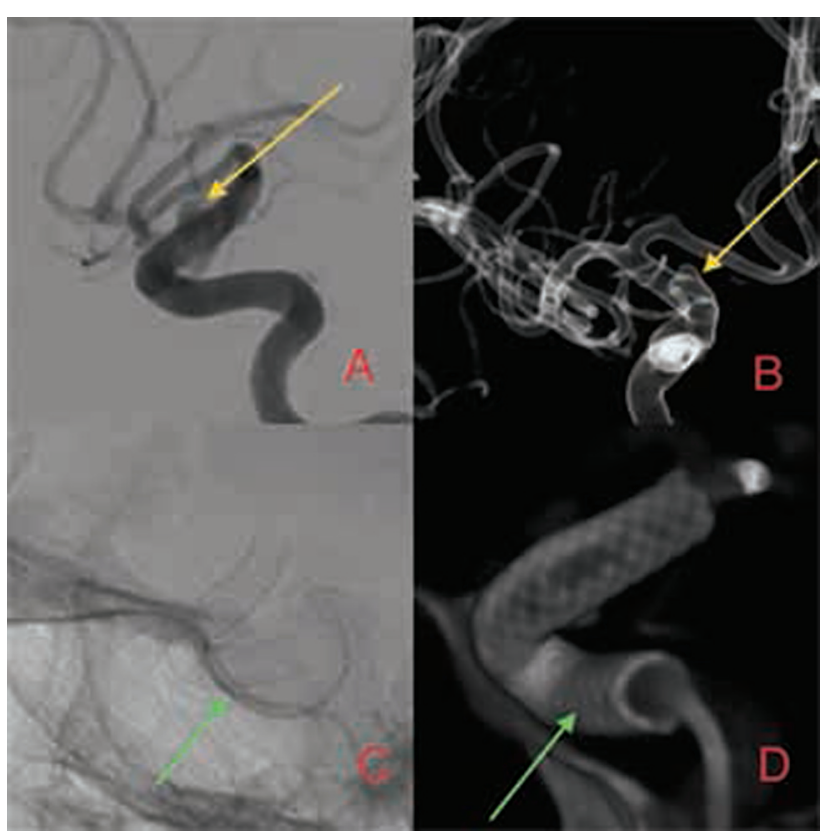

Fig. 1 (A) Lateral angiogram. (B) Three-dimensional rotational angiogram of right internal carotid artery (ICA). Yellow arrow in parts (A) and (B) denotes blister aneurysm in supraclinoid segment of right ICA. (C) Single shot image of flow-diverting device Vaso computed tomography. Green arrow denotes deployed flow diverter with full coverage of the aneurysm neck.

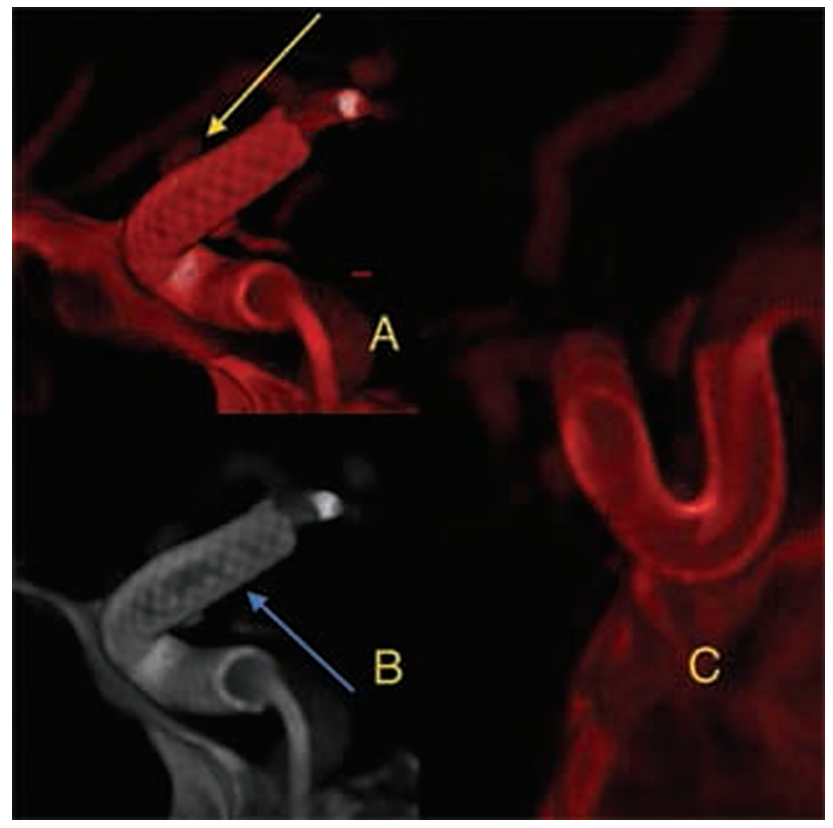

Fig. 2 Intraarterial Vaso computed tomography images (A-C).(A) Yellow arrow denotes the blister aneurysm. (B) Blue arrow denotes deployed flow diverter. (C) Three-dimensional virtual longitudinal sectioning of the device depicting wall conformation.

\section{Funding}

Nil.

Conflict of Interest

None declared.

\section{Acknowledgements}

Prof. Naci Kocer, Istanbul, Turkey, for his guidance.

\section{References}

1 Rouchaud A, Brinjikji W, Cloft HJ, Kallmes DF. Endovascular treatment of ruptured blister-like aneurysms: a systematic review and meta-analysis with focus on deconstructive versus reconstructive and flow-diverter treatments. AJNR Am J Neuroradiol 2015;36(12):2331-2339

2 Peitz GW, Sy CA, Grandhi R. Endovascular treatment of blister aneurysms. Neurosurg Focus 2017;42(06):E12

3 Ansari SA, Aoun SG, Bendok BR. Cone beam computed tomography in the neurointerventional room: beyond vessels. World Neurosurg 2012;77(5-6)659-661

4 Tsuruta W, Matsumaru Y, Hamada Y, Hayakawa M, Kamiya Y. Analysis of closed-cell intracranial stent characteristics using cone-beam computed tomography with contrast material. Neurol Med Chir (Tokyo 2013;53(06):403-408 